\title{
OIKOS
}

Research

\section{Impacts of soil temperature, phenology and plant community composition on invertebrate herbivory in a natural warming experiment}

\author{
Emily Warner, Bryndís Marteinsdóttir, Vigdís F. Helmutsdóttir, Johan Ehrlén, Sinikka I. Robinson and \\ Eoin J. O'Gorman
}

E. Warner (https://orcid.org/0000-0003-2236-9725), Imperial College London, Silwood Park Campus, Berkshire, UK, and: Dept of Plant Sciences, Univ. of Oxford, Oxford, UK. - B. Marteinsdóttir (https://orcid.org/0000-0003-3779-7327), Soil Conservation Service of Iceland, Hella, Iceland. - BM and V. F. Helmutsdóttir, Inst. of Life and Environmental Sciences, Univ. of Iceland, Reykjavik, Iceland. - J. Ehrlén (https://orcid.org/0000-0001-85398967), Dept of Ecology, Environment and Plant Sciences, Stockholm Univ., Stockholm, Sweden. - S. I. Robinson (https://orcid.org/0000-0002-88310497), Faculty of Biological and Environmental Sciences, Univ. of Helsinki, Lahti, Finland. - E. J. O'Gorman (https://orcid.org/0000-0003-4507-5690) $\square$ (e.ogorman@essex.ac.uk), School of Life Sciences, Univ. of Essex, Wivenhoe Park, Colchester, UK.

\section{Oikos}

00: $1-11,2021$

doi: 10.1111/oik.08046

Subject Editor: John Parker Editor-in-Chief: Dries Bonte Accepted 10 June 2021
Species and community-level responses to warming are well documented, with plants and invertebrates known to alter their range, phenology or composition as temperature increases. The effects of warming on biotic interactions are less clearly understood, but can have consequences that cascade through ecological networks. Here, we used a natural soil temperature gradient of $5-35^{\circ} \mathrm{C}$ in the Hengill geothermal valley, Iceland, to investigate the effects of temperature on plant community composition and plantinvertebrate interactions. We quantified the level of invertebrate herbivory on the plant community across the temperature gradient and the interactive effects of temperature, plant phenology (i.e. development stage) and vegetation community composition on the probability of herbivory for three ubiquitous plant species, Cardamine pratensis, Cerastium fontanum and Viola palustris. We found that the percentage cover of graminoids and forbs increased, while the amount of litter decreased, with increasing soil temperature. Invertebrate herbivory also increased with soil temperature at the plant community level, but this was underpinned by different effects of temperature on herbivory for individual plant species, mediated by the seasonal development of plants and the composition of the surrounding vegetation. This illustrates the importance of considering the development stage of organisms in climate change research given the variable effects of temperature on susceptibility to herbivory at different ontogenetic stages.

Keywords: climate change, geothermal gradient, global warming, Hengill, life history, natural experiment, Subarctic, trophic interactions

\section{Introduction}

Mean global surface temperatures are projected to rise by at least $1.5^{\circ} \mathrm{C}$ by 2100 , with the fastest rates of warming in the Arctic region (IPCC 2014). Species-level responses

(C) 2021 Nordic Society Oikos. Published by John Wiley \& Sons Ltd

www.oikosjournal.org 
to warming over the last century have been comprehensively documented, such as altered geographical ranges and phenology, i.e. the seasonal timing of life-cycle events (Visser and Holleman 2001, Parmesan 2006). These changes reflect a combination of direct physiological responses to warming and indirect responses mediated by changes in interspecific interactions. But there is limited understanding of how species interactions will respond to climate change, even though disruption of interactions has the potential to cause cascading effects through ecological networks (Tylianakis et al. 2008, Van der Putten et al. 2010, Kharouba et al. 2018). Antagonistic interactions could be exacerbated or mutualistic interactions disrupted, especially if interacting partners display dissimilar responses to changing climatic cues (Durant et al. 2007, Walther 2010).

Experimental warming of plant communities at northern latitudes has led to increased growth rates (Arft et al. 1999, Klein et al. 2008) and biomass production (Richardson et al. 2002, Brooker and van der Wal 2003), although responses often depend on the type of vegetation (Jónsdóttir et al. 2005, Walker et al. 2006). Warming also leads to changes in plant community composition that can have consequences for higher trophic levels (Richardson et al. 2002, Brooker and van der Wal 2003, Walker et al. 2006). The effects of warming on plants may even be mediated by higher trophic levels (Walther 2010), e.g. the response of an Arctic plant community to warming depended on the presence of herbivores within the system (Post and Pedersen 2008). Direct responses to temperature at one trophic level can also propagate through ecological networks, e.g. warming in Greenland reduced caribou reproductive success because the timing of calving no longer coincided with the onset of plant growth (Post and Forchhammer 2008). Therefore, it is vital to understand how trophic interactions will change with warming in order to predict how species and communities will respond to climate change (Gilman et al. 2010).

Terrestrial invertebrate herbivory is important in structuring plant communities (Wardle and Barker 1997, Allan and Crawley 2011), but climate change is likely to alter the strength of herbivory and the extent and frequency of invertebrate herbivore outbreaks (Bale et al. 2002, Wolf et al. 2008). Evidence from the fossil record shows greater damage to plant tissues during climate warming from the late-Palaeocene to mid-Eocene, suggesting that the activity of insect herbivores increases with temperature (Wilf and Labandeira 1999). Dynamic modelling also suggests that climate change could intensify levels of invertebrate herbivory on vegetation (Wolf et al. 2008). The response of plant-herbivore interactions to future warming is difficult to predict, however, with previous studies emphasising the complexity of the expected response through variable, and often species-specific, effects of temperature on invertebrate herbivory (Kingsolver and Woods 1998, Richardson et al. 2002, Roy et al. 2004, Lemoine et al. 2013, Leckey et al. 2014, Barrio et al. 2016, 2017, Birkemoe et al. 2016).

Herbivorous invertebrates rely on the presence of plant material of a specific age at key points in their life-cycle, therefore synchronous plant and invertebrate responses to altered climatic cues are crucial (Memmott et al. 2007, Van der Putten et al. 2010). There are species-specific examples of strong selection on the timing of insect emergence, ensuring coordination with availability of the required food plant (Visser and Holleman 2001, van Asch et al. 2007). Shifting climatic patterns might disrupt the coincidence of insect emergence and food plant availability, influencing the quality and quantity of food available (van Asch et al. 2007). At larger scales, climate warming mediates insect herbivore outbreaks with ecosystem-level impacts (Karlsson et al. 2004, Jepsen et al. 2008). Climate change could thus facilitate invertebrate range expansions, but phenological mismatches could result in lower fitness and impacts that propagate through an ecosystem (Kharouba et al. 2018).

The effect of temperature on plant-invertebrate interactions will often have consequences for plant fitness, depending on whether plants suffer increased or decreased exposure to herbivory (Bale et al. 2002, Jepsen et al. 2008). For example, changes in the onset of plant growth can alter exposure to herbivores (Post et al. 2009). Advanced onset of growth in common St John's wort Hypericum perforatum due to experimental warming led to decreased damage from insect herbivores (Fox et al. 1999). Conversely, with earlier onset of growth in high Arctic plant communities due to earlier snowmelt, the simultaneous earlier emergence of moths resulted in greater herbivory on mountain avens flowers (Berg et al. 2008).

Natural temperature gradients have been proposed as model systems that substitute space for time in the study of climate warming impacts (Dunne et al. 2003, O'Gorman et al. 2014). They simulate some of the control provided by temperature manipulations in a laboratory setting, whilst maintaining all the processes and variability of natural environments. Here, we used a natural soil temperature gradient of $5-35^{\circ} \mathrm{C}$ in a low Arctic community, dominated by herbaceous plants and bryophytes to investigate the response of plants and invertebrates to environmental warming at high latitudes. We hypothesised (H1) that vegetation community composition would change with increasing soil temperature, with a greater percentage cover of graminoids and litter and a reduction in bryophytes and lichens (Brooker and van der Wal 2003, Walker et al. 2006). We hypothesised (H2) that invertebrate herbivory would increase with increasing soil temperature at both the plant community and species levels (Wilf and Labandeira 1999, Wolf et al. 2008). Finally, we hypothesised (H3) that plant phenology would mediate temperature effects on plant-invertebrate interactions, with less damage from invertebrate herbivores at later stages of development (Fox et al. 1999).

\section{Methods}

\section{Study site}

The study was conducted from May to July 2017 in the Hengill Valley, Iceland $\left(64^{\circ} 3^{\prime} \mathrm{N}, 21^{\circ} 18^{\prime} \mathrm{W}, 350-420 \mathrm{~m}\right.$ a.s.l. $), 40 \mathrm{~km}$ 
east of Reykjavík (Supporting information). Geothermal activity generates a natural gradient of soil temperatures at a fine spatial scale, facilitating the exploration of thermal effects on the terrestrial community without confounding factors such as atmospheric conditions, biogeography and dispersal constraints (O'Gorman et al. 2014, Robinson et al. 2018). Previous research in the study area has shown changes in plant phenology and reductions in the overall diversity of the plant and invertebrate communities as soil temperature increases, although total plant cover and invertebrate biomass are largely unchanged across the temperature gradient (Robinson et al. 2018, Valdés et al. 2019). The vegetation is representative of a low Arctic community, dominated by herbaceous perennial flowering plants and bryophytes, with a flowering season from May to September. The terrestrial fauna is dominated by invertebrates, thus while the area is grazed by sheep from June to September, only invertebrate herbivory was considered in this study. Key invertebrate herbivores at the site include aphids, springtails, scale insects, slugs, moth larvae, leafhoppers and weevils (Supporting information). Survey work conducted during the same time of year as this study showed a similar species richness and abundance of invertebrate herbivores across the soil temperature gradient in Hengill (Supporting information).

Herbivory assessments were made at the plant community and species levels. We focused on three plant species with a widespread occurrence across the temperature gradient: cuckooflower Cardamine pratensis, common mouse-ear Cerastium fontanum and marsh violet Viola palustris. The three species have different growth forms and expected susceptibilities to invertebrate herbivory (Turcotte et al. 2014). Cardamine pratensis has pinnate leaves with multiple leaflets up to $1 \mathrm{~cm}$ wide and individuals in our study had up to 20 flowering stems and 30 basal leaves. Cerastium fontanum is a densely hairy herb with runners, erect flowering shoots and paired leaves that are up to $1 \mathrm{~cm}$ wide, while individuals in our study had up to 30 runners and 250 leaves. Viola palustris has hairless kidney-shaped leaves that are $1-4 \mathrm{~cm}$ wide and individuals in our study had up to 14 leaves (Supporting information).

\section{Experimental design}

Fourteen experimental plots measuring 66-210 $\mathrm{m}^{2}$ were established within a $1 \mathrm{~km}^{2}$ area of the Hengill valley in May 2017 (Supporting information). Plot locations were chosen to ensure that individuals of the focal plant species were distributed evenly across a gradient of soil temperatures, whilst also aiming for within-plot variation in temperature where possible. Thirty individuals per species of $C$. pratensis, $C$. fontanum and $V$. palustris were marked in each of ten plots, using a stratified random sampling method where individuals were randomly selected, but the full range of within-plot soil temperatures was represented. For the community-level herbivory assessments, five $50 \times 50 \mathrm{~cm}$ quadrats (hereafter community-level quadrats) were marked at random points in eight of the plots that best captured the full temperature gradient (Supporting information).

\section{Environmental variables}

Soil temperature was recorded at $12 \mathrm{~cm}$ depth at five points within each community-level herbivory quadrat and during each herbivory survey at every marked individual of C. pratensis, C. fontanum and V. palustris, using a soil temperature probe. Percentage soil moisture was recorded in each community-level herbivory quadrat using an ML3 ThetaProbe and HH2 Handheld Readout Unit. To quantify soil $\mathrm{pH}$ and nutrient content, five soil cores were taken in each community-level herbivory quadrat, using a $2 \mathrm{~cm}$ diameter soil auger, sampling $2-10 \mathrm{~cm}$ deep and homogenising the five cores prior to analysis. Nitrate and ammonium were extracted from fresh soil using $2 \mathrm{M} \mathrm{KCl}$ solution with a 5:1 soil-to-solution ratio (Blakemore et al. 1987). Phosphate was extracted from fresh soil using an ammonium lactate-acetic acid buffer $(\mathrm{pH} 3.75)$ with a 10:1 soil-to-solution ratio (Egnér et al. 1960). Nutrient concentrations were assessed colourimetrically, with detection limits of $0.17 \mathrm{mg} \mathrm{kg}^{-1}$ for nitrate and ammonium, and $0.30 \mathrm{mg} \mathrm{kg}^{-1}$ for phosphate. The remainder of the soil was dried for $13 \mathrm{~h}$ at $80^{\circ} \mathrm{C}$, after which time $10 \mathrm{~g}$ was added to $25 \mathrm{ml}$ deionised water, shaken vigorously and left for $12 \mathrm{~h}$ before measurement with a $\mathrm{pH}$ probe (Blakemore et al. 1987).

\section{Quantifying plant phenology and vegetation communities}

The floral development stage of each marked individual of $C$. pratensis, $C$. fontanum and $V$. palustris was estimated weekly throughout the study as a measure of plant phenology. The development stages were denoted as follows: 1) only vegetative growth, plant $<2 \mathrm{~cm} ; 2$ ) only vegetative growth, plant $>2 \mathrm{~cm}$; 3) buds just starting to form, very small, close to leaves; 4) buds at medium size; 5) buds large, but still completely closed; 6) buds large and starting to open; 7) buds large and opening more, petals > sepals; 8) at least one flower opened; 9) all flowers opened, none yet wilted; and 10) flowers starting to wilt. The aboveground vegetation community was also surveyed in association with each community-level quadrat from 6 to 7 June, and each individual marked plant (i.e. species-level quadrats) from 20 to 27 May, using $50 \times 50$ $\mathrm{cm}$ quadrats. Percentage cover of functional groups of vegetation (bryophytes, forbs, graminoids, lichens, litter and bare ground) was visually estimated at ground level as the midpoint of the following cover classes: $0-1,1-2,2-5,5-10$, $10-25,25-50,50-75,75-95$ and $95-100 \%$ (after Peet et al. 1998).

\section{Quantifying herbivory}

Leaf herbivory was quantified using a 'standing' measure of damage to leaves at each sampling time-point (Turcotte et al. 2014). The community-level herbivory assessment was conducted on 19 June. The number of damaged plants was recorded out of 100 random individuals, selected using a $10 \times 10$ grid within each $50 \times 50 \mathrm{~cm}$ quadrat. For the 
species-level herbivory assessment, individual marked plants were surveyed for signs of invertebrate herbivory every two weeks from 30 May to 2 July, generating three time-points per species. At each survey, all marked individuals for each species were assessed within a 48-h period. Plants were recorded as damaged or not damaged by invertebrate herbivores at each time-point. We only saw evidence for defoliation due to biting, with no leaf mining or galling. The percentage of plants exhibiting damage ranged from 30 to $60 \%$ for each plant species at each sampling time-point, so our measure of herbivory was never in danger of saturating. The assessment of herbivore damage was only recorded on healthy, fully expanded leaves; evidence of damage on wilted leaves was not included in the overall estimation of herbivore damage, as damage to these leaves could not be exclusively attributed to invertebrate herbivory. To avoid overestimation of the level of invertebrate herbivory, loss of entire leaves or leaflets was only categorised as herbivore damage if part of the petiole was still present with invertebrate bite marks evident (Turcotte et al. 2014).

\section{Statistical analysis}

All statistical analyses were carried out in $\mathrm{R}$ ver. 4.0.2 $<$ www.r-project.org $>$. Plant data with corresponding soil temperatures $>35^{\circ} \mathrm{C}$ were excluded because these extreme temperatures are less relevant in a climate change context. This excluded one of 40 community-level quadrats and 20 of 984 species-level quadrats. A Mantel test was used to check for spatial structure in the soil temperature data by comparing pairwise distances between experimental plots with pairwise temperature differences after taking the average of all the soil temperatures recorded in each plot ('mantel function in the 'vegan' package with "method = "spearman" to account for non-normality of the distance data).

Associations between temperature and other measured environmental variables (i.e. soil moisture, $\mathrm{pH}$ and concentrations of nitrate, ammonium and phosphate) were tested using Pearson correlations and the false discovery rate correction for multiple testing ('cor.test' and 'p.adjust' functions with 'method = "fdr" in the 'stats' package). Note that the false discovery rate is not as conservative as the Bonferroni correction and thus less likely to discard significant effects when correcting for multiple testing (Benjamini and Hochberg 1995). Associations between environmental variables and the percentage cover for each vegetation group sampled in the community-level quadrats $(n=39)$ were also explored using Pearson correlations.

The relationship between soil temperature and percentage cover for each vegetation group in the species-level quadrats $(n=964)$ was assessed using linear mixed effects models (LMM), with soil temperature as a continuous fixed effect and a random intercept for experimental plot ('lme' function in the 'nlme' package). The midpoints of the percentage cover data were converted to proportions and logit transformed to meet the assumption of normality of the model residuals. Detrended correspondence analysis (DCA) was also used to produce a measure of vegetation community composition for both the community- and species-level quadrats ('decorana' function in the 'vegan' package). The input was a site by vegetation matrix, based on the midpoints of the cover classes for each vegetation group, and the first DCA axis was used as a measure of vegetation community composition in subsequent analyses.

The major drivers of herbivory at the community level were explored using LMM with a random intercept for experimental plot. We explored the main and interactive effects of soil temperature and vegetation community composition as continuous fixed effects to explain the proportion of plants damaged per quadrat, dropping the interaction term from the model if it was not significant (Crawley 2012).

The major drivers of herbivory at the species level were explored using generalised linear mixed effects models (GLMM) for each species with a random intercept for plant identity nested within experimental plot nested within sampling time-point, and a binomial error structure and logit link ('glmer' function in the 'lmet package). We explored the main effects of soil temperature (a continuous fixed effect), plant phenology (a discrete fixed effect with integer values for each development stage) and vegetation community composition (a continuous fixed effect), plus the interactive effects of temperature:phenology and temperature:composition. We also included a second-order polynomial term for phenology to account for possible reductions in herbivory in later stages of development. We dropped any non-significant second-order polynomial or interaction terms from the model, starting with the least significant higher-order term (Crawley 2012). Note that we used the measure of plant phenology that was closest in time to our measure of herbivory in these analyses.

\section{Results}

\section{Environmental variables}

There was no significant correlation between pairwise distance and temperature difference between plots (Mantel test: $r=0.15 ; p=0.103)$. There was also no significant correlation between temperature and soil moisture (Pearson correlation: $\mathrm{r}=-0.15 ; \mathrm{p}=0.533$ ), $\mathrm{pH}$ (Pearson correlation: $\mathrm{r}=0.20$; $\mathrm{p}=0.580$ ), nitrate (Pearson correlation: $\mathrm{r}=0.02 ; \mathrm{p}=0.907$ ), ammonium (Pearson correlation: $r=-0.10 ; p=0.664$ ) or phosphate (Pearson correlation: $\mathrm{r}=0.35 ; \mathrm{p}=0.143$ ).

\section{Vegetation community}

There was no significant relationship between temperature and the percentage cover of bryophytes (LMM: $t=-0.98$; $\mathrm{p}=0.329$; Fig. 1a) or lichens (LMM: $t=-1.53 ; \mathrm{p}=0.127$; Fig. 1d) in the species-level quadrats. There was a significant increase in the percentage cover of forbs (LMM: $t=6.88$; $\mathrm{p}<0.001$; marginal $\mathrm{r}^{2}=0.10$; conditional $\mathrm{r}^{2}=0.48$; Fig. 1b), graminoids (LMM: $\mathrm{t}=6.32 ; \mathrm{p}<0.001 ;$ marginal $\mathrm{r}^{2}=0.09$; 
(a) Bryophytes

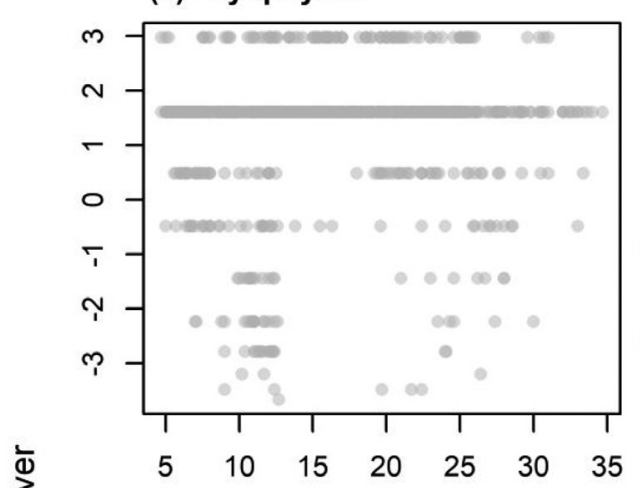

(c) Graminoids

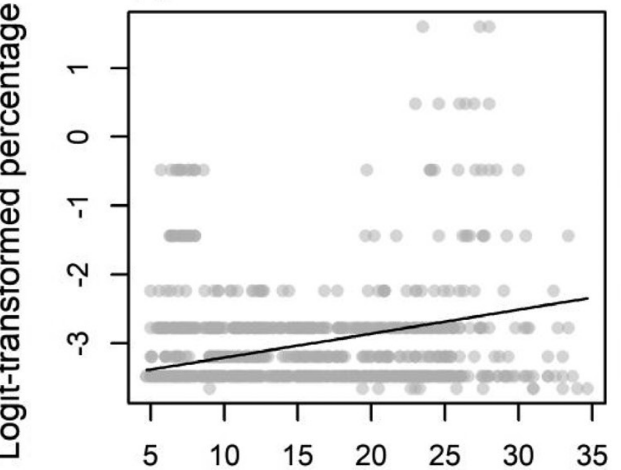

(e) Litter

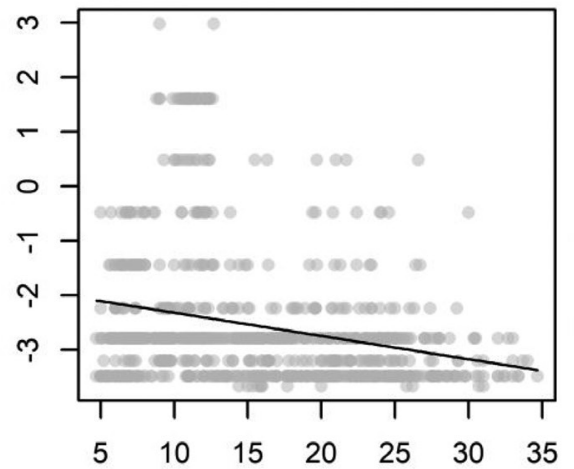

(b) Forbs

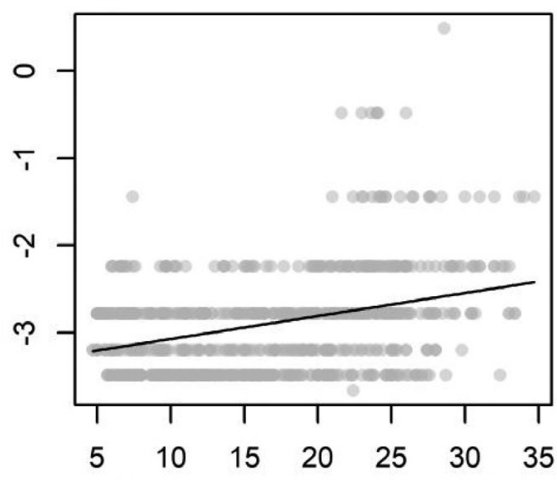

(d) Lichens

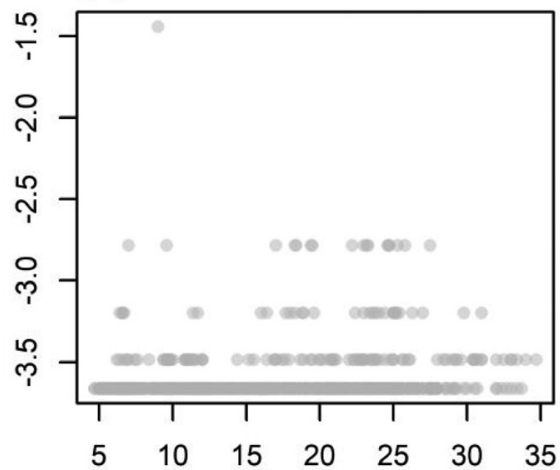

(f) Bare ground

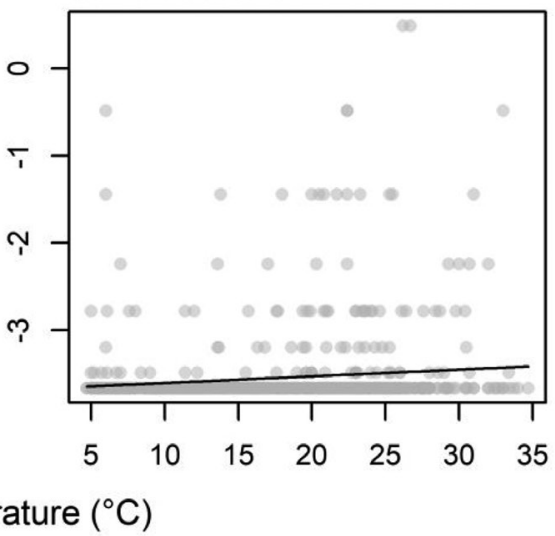

Figure 1. Relationships between temperature and the percentage cover of (a) bryophytes, (b) forbs, (c) graminoids, (d) lichens, (e) litter and (f) bare ground. Logit-transformed midpoints of percentage cover classes are shown on the $y$-axis and only significant trendlines for forbs $\left(y=0.026 x-3.34\right.$; marginal $\mathrm{r}^{2}=0.10$; conditional $\left.\mathrm{r}^{2}=0.48\right)$, graminoids $\left(y=0.035 x-3.56\right.$; marginal $\mathrm{r}^{2}=0.09$; conditional $\left.\mathrm{r}^{2}=0.46\right)$, litter $\left(y=-0.043 x-1.89\right.$; marginal $\mathrm{r}^{2}=0.02$; conditional $\left.\mathrm{r}^{2}=0.62\right)$ and bare ground $\left(y=-0.008 x-3.68\right.$; marginal $\mathrm{r}^{2}=0.06$; conditional $\left.\mathrm{r}^{2}=0.09\right)$ are visualised in the figure.

conditional $r^{2}=0.46$; Fig. 1c) and bare ground (LMM: $\mathrm{t}=2.54 ; \mathrm{p}=0.011 ;$ marginal $\mathrm{r}^{2}=0.02$; conditional $\mathrm{r}^{2}=0.09$; Fig. 1f), and a significant decrease in the percentage cover of litter (LMM: $t=-5.86 ; p<0.001 ;$ marginal $r^{2}=0.06$; conditional $\mathrm{r}^{2}=0.62$; Fig. 1e) with increasing soil temperature. Soil moisture was positively correlated with graminoids and negatively correlated with forbs in the community-level quadrats, whilst phosphate was negatively correlated with bryophytes (Supporting information).
For both the community- and species-level quadrats, negative values of DCA axis 1 corresponded to communities dominated by bryophytes, lichens and forbs, while positive values of DCA axis 1 corresponded to communities dominated by litter (Supporting information). There was only a significant (but weak) effect of temperature on vegetation community composition in the species-level quadrats $(\mathrm{p}<$ $0.001, r^{2}=0.02$ ), with no effect of temperature in the community-level quadrats $\left(p=0.228, r^{2}=0.08\right)$. 


\section{Herbivory}

In the community-level quadrats, $24 \pm 11 \%$ (mean \pm standard deviation, SD) of plants exhibited damage by invertebrate herbivores. The optimal model describing the proportion of herbivory at the plant community-level included the main effects of soil temperature and plant community composition only (marginal $r^{2}=0.21$; conditional $\left.r^{2}=0.21\right)$. There was a significant increase in the proportion of plants exhibiting damage by herbivores with increasing soil temperature (LMM: $t=3.06 ; p=0.005$; Fig. 2), with no significant effect of plant community composition (LMM: $\mathrm{t}=1.58 ; \mathrm{p}=0.126$ ).

For Cardamine pratensis, $44 \pm 3 \%$ (mean \pm SD) of plants exhibited damage by invertebrate herbivores across all sampling time-points. The optimal model describing the probability of herbivory for $C$. pratensis included the main effects of temperature, phenology and plant community composition only (marginal $r^{2}=0.06$; conditional $r^{2}=0.21$ ). There was a significant increase in the probability of damage to C. pratensis by herbivores with increasing soil temperature (GLMM: $\mathrm{t}=2.14 ; \mathrm{p}=0.033$; Fig. 3a), more advanced development stage (GLMM: $t=2.79 ; p=0.005$; Fig. $3 b$ ), and as the vegetation community became increasingly dominated by litter (GLMM: $\mathrm{t}=3.01 ; \mathrm{p}=0.003$; Fig. 3c).

For Cerastium fontanum, $33 \pm 3 \%$ (mean $\pm \mathrm{SD}$ ) of plants exhibited damage by invertebrate herbivores across all sampling time-points. The optimal model describing the probability of herbivory for $C$. fontanum included the main effects of temperature, phenology (first- and second-order polynomial terms) and plant community composition only (marginal $r^{2}=0.09$; conditional $r^{2}=0.17$ ). There was a significant reduction in the probability of damage to C. fontanum

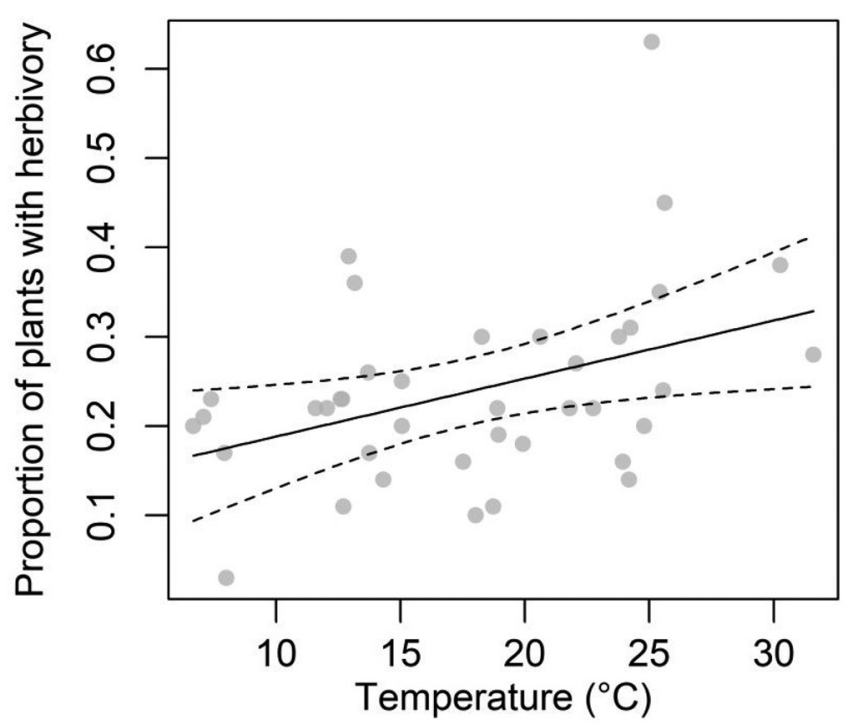

Figure 2. Relationship between temperature and the proportion of plants in the community-level quadrats exhibiting damage by invertebrate herbivores $\left(y=0.0077 x+0.1014\right.$; marginal $r^{2}=0.21$; conditional $\left.\mathrm{r}^{2}=0.21\right)$. by herbivores with increasing soil temperature (GLMM: $\mathrm{t}=-3.48 ; \mathrm{p}<0.001$; Fig. 3d). There was an increase in the probability of damage to $C$. fontanum by herbivores up to development stage 7 (GLMM first-order polynomial term: $\mathrm{t}=3.00 ; \mathrm{p}=0.003)$, with a reduction in later stages (GLMM second-order polynomial term: $\mathrm{t}=-2.61 ; \mathrm{p}=0.009$; Fig. 3e). There was also an increase in the probability of damage to C. fontanum by herbivores as the vegetation community became increasingly dominated by litter (GLMM: $t=2.56$; $\mathrm{p}=0.011$; Fig. 3f).

For Viola palustris, $52 \pm 10 \%$ (mean \pm SD) of plants exhibited damage by invertebrate herbivores across all sampling time-points. The optimal model describing the probability of herbivory for $V$. palustris included the main effects of temperature, phenology and plant community composition, and the interactive effect of temperature $\times$ phenology (marginal $r^{2}=0.06$; conditional $r^{2}=0.12$ ). There was a significant increase in the probability of damage to $V$. palustris by herbivores with increasing soil temperature overall (GLMM: $\mathrm{t}=4.22 ; \mathrm{p}<0.001 ;$ Fig. 3g) and more advanced development stage (GLMM: $t=2.62 ; \mathrm{p}=0.009$; Fig. $3 \mathrm{~h}$ ), with a marginally non-significant increase as the vegetation community became increasingly dominated by litter (GLMM: $t=1.78$; $p=0.075$; Fig. 3i). The significant interactive effect of temperature and phenology (GLMM: $t=-2.20 ; p=0.028)$ was driven by an increase in the probability of damage to $V$. palustris by herbivores with increasing soil temperature in the early stages of development, but a decline in the probability of damage in the later stages of development (Fig. 4).

\section{Discussion}

We considered the impact of soil temperature on plant communities and plant-invertebrate interactions. We found that soil temperature altered plant community composition, increasing the dominance of forbs and graminoids, and reducing the amount of litter. We found general support for stronger plant-invertebrate interactions at the community level in warmer environments, but with variable effects depending on individual plant species. Invertebrate herbivory increased with soil temperature for Cardamine pratensis and Viola palustris, but decreased with temperature for Cerastium fontanum. All three species were also more susceptible to herbivory as they developed (though $C$. fontanum was less susceptible in the later stages of development) and when there was a higher proportion of litter in the surrounding environment. Plant phenology played a crucial role in determining the thermal sensitivity of herbivory in $V$. palustris, with contrasting responses at early and late stages of development. This illustrates the importance of considering the entire life-cycle of organisms in climate change research, given their variable susceptibility to herbivory at different ontogenetic stages.

There was partial support for our first hypothesis, with an increase in the percentage cover of graminoids with increasing soil temperature. Grasses, which dominate the graminoids in our study system, have also been shown to increase 
(a) C. pratensis - temperature

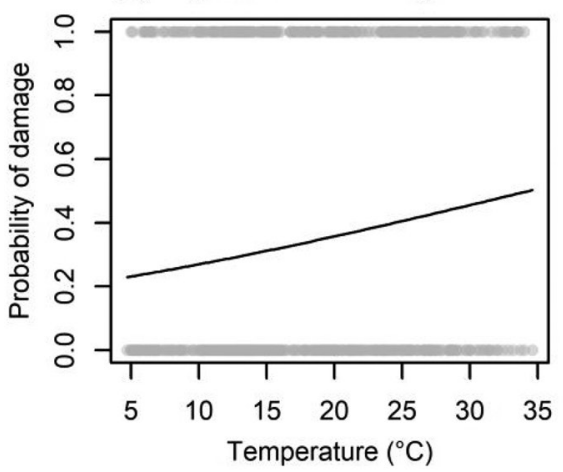

(d) C. fontanum - temperature

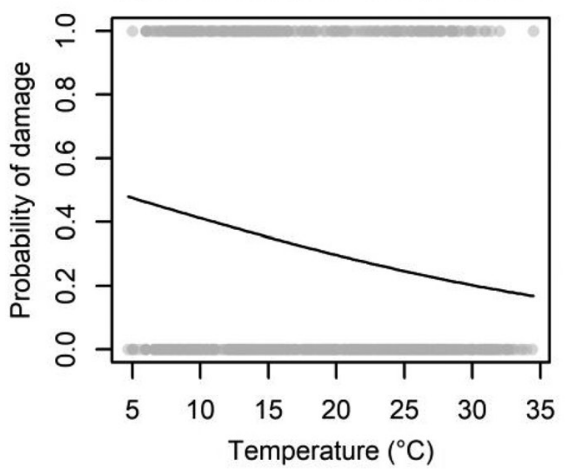

(g) V.palustris - temperature

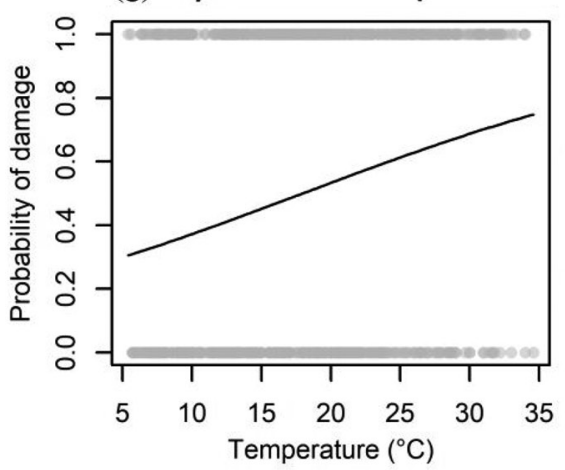

(b) C. pratensis - phenology

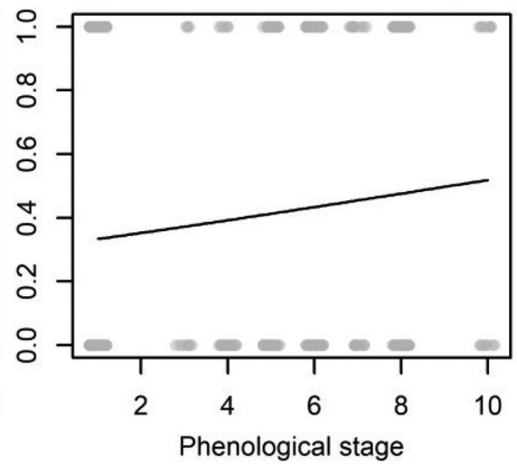

(e) C. fontanum - phenology

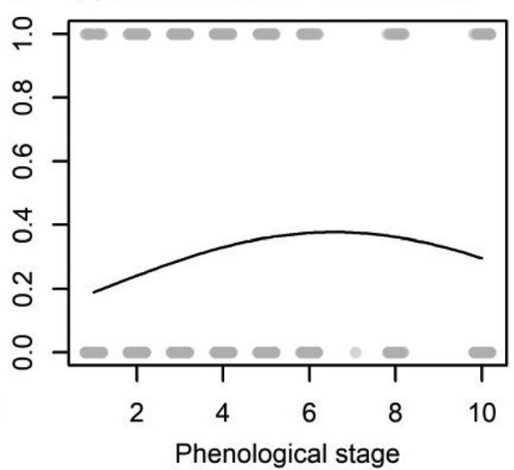

(h) V.palustris - phenology

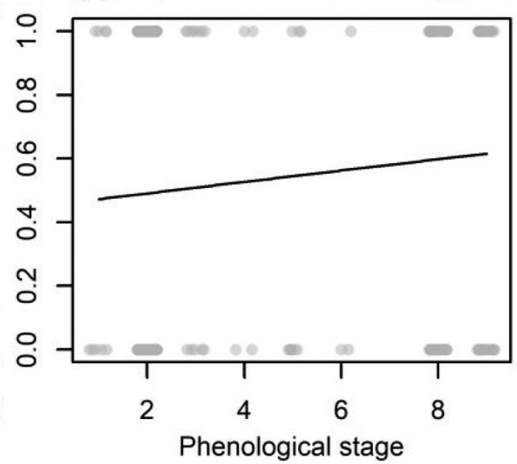

(c) C. pratensis - composition

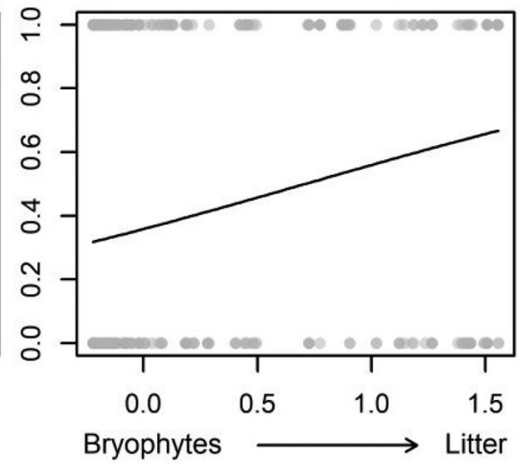

(f) C. fontanum - composition

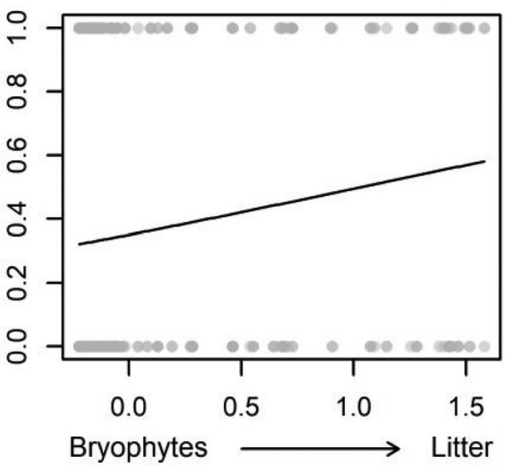

(i) V.palustris - composition

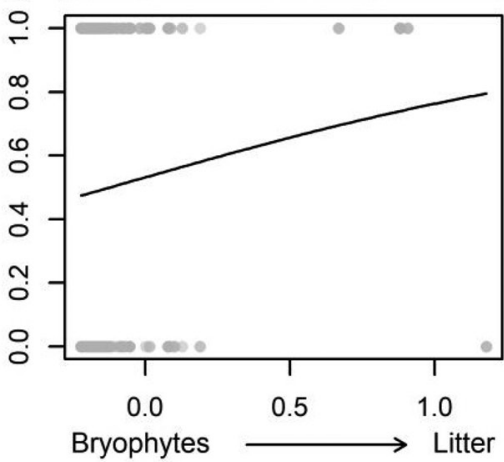

Figure 3. The main effects of temperature, phenology and vegetation community composition on the probability of damage to Cardamine pratensis $(\mathrm{a}-\mathrm{c})$, Cerastium fontanum $(\mathrm{d}-\mathrm{f})$ and Viola palustris $(\mathrm{g}-\mathrm{i})$ by invertebrate herbivores. Phenology is shown as increasing stages of development from small vegetative (stage 1) to the wilting of flowers (stage 10). Vegetation community composition is shown as the first DCA axis of the species-level quadrats, with negative or smaller values indicating communities dominated by bryophytes, lichens and forbs and larger positive values indicating communities dominated by litter (Supporting information). Trendlines are visualised at the median values for other explanatory variables in the model.

with experimental warming in the Arctic region (Brooker and van der Wal 2003, Walker et al. 2006). There was no effect of soil temperature on the percentage cover of bryophytes or lichens, however, which is in contrast to Walker et al. (2006) who found a reduction in the cover of both groups following warming at high latitudes. The increase in percentage cover of forbs with increasing temperature may be driven by increased growth rates, with forbs exhibiting the strongest increases in vegetation growth in warmed tundra communities (Arft et al.
1999, Walker et al. 2006, Winkler et al. 2016). Given that bryophytes were the dominant vegetation class throughout the study site (Fig. 2), an increase in the percentage cover of forbs in warmer areas should increase habitat availability and food quality for invertebrate herbivores (Lawton 1983, Southwood et al. 1986). This could be an important factor in attracting insect herbivores to warmer habitats, as a potential indirect effect of temperature on stronger plant-invertebrate interactions (Moise and Henry 2010). The reduction 
(a) Development stage 1

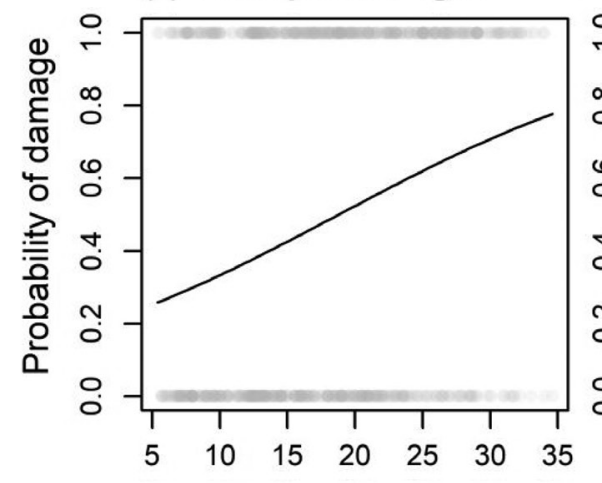

(b) Development stage 5

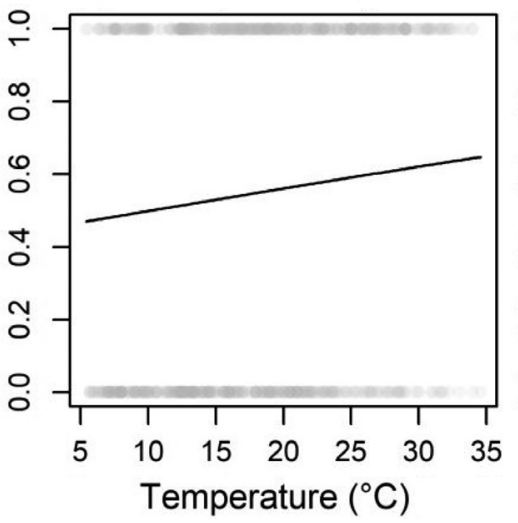

(c) Development stage 9

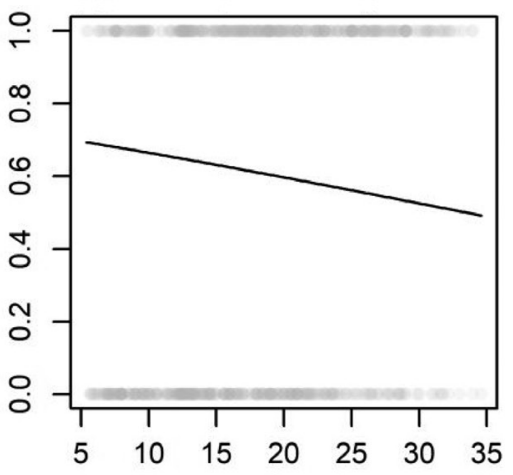

Figure 4. The interactive effect of temperature and phenology on the probability of damage to V. palustris by invertebrate herbivores. Temperature effects are visualised at the (a) first, (b) middle and (c) last stage of development observed during the current study. See the Supporting information for temperature effects at all development stages.

in litter with increasing soil temperatures was likely due to faster decomposition rates at higher temperatures, as previously shown in tundra ecosystems (Hobbie 1996). Lower quantities of litter are associated with higher germination rates (Xiong and Nilsson 1999), but may increase the risk of invertebrate herbivory for individual plants (Fig. 3c, f, i).

Invertebrate herbivory increased with increasing temperature at the plant community level, in support of our second hypothesis. Strengthening of consumer-resource interactions with increasing temperature has been widely observed in functional response experiments (Rall et al. 2012), due to the higher metabolic demands of life in warmer environments (Brown et al. 2004). Stronger plant-herbivore interactions at higher temperatures may also be driven by changes in the invertebrate community, but we found no evidence for altered abundance or species richness of invertebrate herbivores across the temperature gradient here (Supporting information). This suggests that changes in the energy requirements and feeding rates of invertebrates should be the major factor driving these results, although changes in the species identity and relative abundance of insect herbivores across the soil temperature gradient could also be a factor. Stronger plant-herbivore interactions can reverse the positive effects of temperature on plant growth (O'Connor 2009), disrupt temperature effects on plant community composition (Post and Pedersen 2008), and shape plant productivity responses to warming (Post et al. 2009). Vegetation community composition may also form a feedback loop by influencing invertebrate feeding preferences (Loranger et al. 2013), whereby desirable plant species attract herbivores and less attractive vegetation masks the detection of desirable plants (Hambäck et al. 2000, Finch and Collier 2012). Nevertheless, we found no independent effects of the surrounding vegetation community composition on invertebrate herbivory at the community-level here, suggesting mainly indirect effects on invertebrate herbivory mediated by temperature.

There were contrasting effects of temperature on the probability of herbivory for each plant species, with inconsistent effects of warming on invertebrate herbivory at the species-level also shown across previous research at high latitudes (Leckey et al. 2014, Birkemoe et al. 2016, Barrio et al. 2017). This may be driven by individual plant traits, with life history, morphology and physical defence known to be correlated with resistance to herbivory (Wardle et al. 1998, Carmona et al. 2011). For example, C. fontanum has densely hairy leaves, which may limit its appeal to invertebrate herbivores (Fordyce and Agrawal 2001, Hanley et al. 2007) and contribute to the lower risk of herbivory that was observed at higher temperatures compared to the other smooth-leaved species. In contrast, the susceptibility of $C$. pratensis to invertebrate herbivores has been demonstrated experimentally, with lower percentage cover in their presence compared to their absence, whereas $C$. fontanum actually increased in percentage cover in the presence of invertebrate herbivores (Stein et al. 2010).

Probability of damage increased with advancing development over the flowering period for both $C$. pratensis and $V$. palustris, suggesting that the plants became more susceptible to herbivory as they developed. This contrasts with other research showing greater invertebrate herbivore damage on young plants due to their weaker defences (Boege and Marquis 2005). Our finding could reflect a change in the visibility of the plants to herbivores as they grow or a higher abundance of invertebrates at the study site as the season develops. Greater invertebrate damage has been demonstrated at later stages of development in other Cardamine species, accompanied by negative effects on vegetative propagation (Collinge and Louda 1988), which highlights the potential consequences of increased invertebrate herbivory for plant fitness. The reduction in herbivore damage at later development stages for $C$. fontanum (Fig. 3e) could suggest greater rates of plant tissue regeneration or lower invertebrate attack rates later in the season or as flowers begin to wilt. The nutritional quality of $C$. fontanum decreases with maturity (Kramberger and Klemenčič 2003), which lends some support for a lower preference of invertebrates for this species over time.

In support of our third hypothesis, plant development stage influenced temperature effects on herbivory for $V$. palustris. 
Here, plants were more vulnerable to invertebrate herbivores in warmer soils at earlier development stages, whereas they were more vulnerable in cooler soils at later stages. Warming has been shown to reduce the nutritional quality of leaves, by decreasing the amount of leaf biomass relative to stems (Veteli et al. 2002). Leaves from warmer regions also tend to be tougher, with less nitrogen content, and more tannins and alkaloids (Coley 1998). A similar response in $V$. palustris may make the plant less appealing to herbivores at higher temperatures as it grows. Interactive effects of temperature and herbivory have been shown on plant phenology, with herbivores altering impacts of warming on plant height and seed production (Lemoine et al. 2017). We believe our study is the first demonstration of a feedback response, such that plant phenology also alters the effect of temperature on herbivory. This illustrates the complex and reciprocal nature of plant-herbivore interactions and the potential for phenological mismatches in a warmer climate to alter the dynamics of both plant and invertebrate communities (de Sassi et al. 2012). Note that our study most likely quantified accumulated damage by herbivores across development stages and so future research should test for different rates of herbivory at each stage for a deeper understanding of how phenology might alter temperature effects on herbivory.

We have shown that increasing temperature has different effects on plant-invertebrate interactions at high latitudes depending on the plant species, but the overall response at the community level was greater invertebrate herbivory in warmer environments. In tropical ecosystems, where invertebrate herbivores play an even stronger role in structuring plant communities, and are much closer to their thermal limits, temperature-induced changes in plant-invertebrate interactions could have more severe community-level consequences (Coley and Barone 1996, Deutsch et al. 2008). Furthermore, future warming will be accompanied by changes in other climatic variables, such as precipitation, $\mathrm{CO}_{2}$ levels and the frequency of extreme events, eliciting physiological and behavioural responses in plants and invertebrates that may modulate the overall response to warming (Bale et al. 2002). As research into the impacts of climate change broadens, it is important to consider that responses can vary at different life-cycle stages of the individual organisms involved. Future research should also aim to disentangle the complex feedbacks between temperature effects on plant communities and invertebrate herbivores by quantifying changes in the structure of ecological networks.

Acknowledgements - We thank Gísli Már Gíslason and Jón S. Ólafsson for providing advice, research support and facilities, and Arngrímur Thorlacius at Efnagreining for conducting the soil nutrient analysis.

Funding - We acknowledge the funding support of NERC (NE/ L011840/1, NE/M020843/1), the British Ecological Society (40094884, 7283/5350, SR16/1152), the Royal Society (RG140601), the Energy research fund from the National Power Company of Iceland, and a University of Iceland post-doctoral grant.

Conflicts of interest - All authors contributed equally to the study.

\section{Author contributions}

Emily Warner: Data curation (equal); Formal analysis (equal); Investigation (equal); Methodology (equal); Writing - original draft (lead). Bryndis Marteinsdottir: Conceptualization (lead); Data curation (supporting); Funding acquisition (lead); Investigation (supporting); Methodology (lead); Supervision (supporting); Writing - review and editing (supporting). Vigdís F. Helmutsdóttir: Data curation (supporting); Investigation (supporting); Methodology (supporting); Writing - review and editing (supporting). Johan Ehrlén: Conceptualization (supporting); Funding acquisition (supporting); Investigation (supporting); Methodology (supporting); Supervision (supporting); Writing - review and editing (supporting). Sinikka I. Robinson: Conceptualization (supporting); Funding acquisition (supporting); Investigation (supporting); Methodology (supporting); Supervision (supporting); Writing - review and editing (supporting). Eoin J. O'Gorman: Conceptualization (lead); Data curation (supporting); Formal analysis (supporting); Funding acquisition (lead); Investigation (supporting); Methodology (supporting); Supervision (lead); Writing - review and editing (lead).

\section{Data availability statement}

Data are archived with the NERC Environmental Information Data Centre: <https://doi.org/10.5285/ da5d7028-2aec-4da2-96ff-f347a0dfa77e $>$.

\section{References}

Allan, E. and Crawley, M. J. 2011. Contrasting effects of insect and molluscan herbivores on plant diversity in a long-term field experiment. - Ecol. Lett. 14: 1246-1253.

Arft, A. et al. 1999. Responses of tundra plants to experimental warming: meta-analysis of the international tundra experiment. - Ecol. Monogr. 69: 491-511.

Bale, J. S. et al. 2002. Herbivory in global climate change research: direct effects of rising temperature on insect herbivores. Global Change Biol. 8: 1-16.

Barrio, I. C. et al. 2016. Warming the tundra: reciprocal responses of invertebrate herbivores and plants. - Oikos 125: 20-28.

Barrio, I. et al. 2017. Background invertebrate herbivory on dwarf birch (Betula glandulosa-nana complex) increases with temperature and precipitation across the tundra biome. - Polar Biol. 40: 2265-2278.

Benjamini, Y. and Hochberg, Y. 1995. Controlling the false discovery rate: a practical and powerful approach to multiple testing. - J. R. Stat. Soc. B 57: 289-300.

Berg, T. B. et al. 2008. High-Arctic plant-herbivore interactions under climate influence. - Adv. Ecol. Res. 40: 275-298.

Birkemoe, T. et al. 2016. Experimental warming increases herbivory by leaf-chewing insects in an alpine plant community. - Ecol. Evol. 6: 6955-6962.

Blakemore, L. et al. 1987. Methods for chemical analysis of soils. - New Zealand Soil Bureau Scientific, Report 80, N. Z. Soc. Soil Sci., New Zealand, Lower Hutt, p. 103. 
Boege, K. and Marquis, R. J. 2005. Facing herbivory as you grow up: the ontogeny of resistance in plants. - Trends Ecol. Evol. 20: 441-448.

Brooker, R. and van der Wal, R. 2003. Can soil temperature direct the composition of high arctic plant communities? - J. Veg. Sci. 14: $535-542$.

Brown, J. H. et al. 2004. Toward a metabolic theory of ecology. Ecology 85: 1771-1789.

Carmona, D. et al. 2011. Plant traits that predict resistance to herbivores. - Funct. Ecol. 25: 358-367.

Coley, P. D. 1998. Possible effects of climate change on plant/ herbivore interactions in moist tropical forests. - Clim. Change 39: 455-472.

Coley, P. D. and Barone, J. 1996. Herbivory and plant defenses in tropical forests. - Annu. Rev. Ecol. Syst. 27: 305-335.

Collinge, S. and Louda, S. 1988. Herbivory by leaf miners in response to experimental shading of a native crucifer. - Oecologia 75: 559-566.

Crawley, M. J. 2012. The R book. - Wiley.

de Sassi, C. et al. 2012. Plant-mediated and nonadditive effects of two global change drivers on an insect herbivore community. - Ecology 93: 1892-1901.

Deutsch, C. A. et al. 2008. Impacts of climate warming on terrestrial ectotherms across latitude. - Proc. Natl Acad. Sci. USA 105: 6668-6672.

Dunne, J. A. et al. 2003. Subalpine meadow flowering phenology responses to climate change: integrating experimental and gradient methods. - Ecol. Monogr. 73: 69-86.

Durant, J. M. et al. 2007. Climate and the match or mismatch between predator requirements and resource availability. Clim. Res. 33: 271-283.

Egnér, H. et al. 1960. Investigation of the soil test analysis for the assessment of soil nutrients, II. Chemical methods for the extraction of phosphorous and potassium. - Ann. R. Swed. Agric. Univ. 26: 199-215.

Finch, S. and Collier, R. H. 2012. The influence of host and nonhost companion plants on the behaviour of pest insects in field crops. - Entomol. Exp. Appl. 142: 87-96.

Fordyce, J. A. and Agrawal, A. A. 2001. The role of plant trichomes and caterpillar group size on growth and defence of the pipevine swallowtail Battus philenor. - J. Anim. Ecol. 70: 997-1005.

Fox, L. R. et al. 1999. Direct and indirect effects of climate change on St John's wort, Hypericum perforatum L. (Hypericaceae). Oecologia 120: 113-122.

Gilman, S. E. et al. 2010. A framework for community interactions under climate change. - Trends Ecol. Evol. 25: 325-331.

Hambäck, P. A. et al. 2000. Associational resistance: insect damage to purple loosestrife reduced in thickets of sweet gale. - Ecology 81: 1784-1794.

Hanley, M. E. et al. 2007. Plant structural traits and their role in anti-herbivore defence. - Perspect. Plant Ecol. Evol. Syst. 8: 157-178.

Hobbie, S. E. 1996. Temperature and plant species control over litter decomposition in Alaskan tundra. - Ecol. Monogr. 66: 503-522.

IPCC 2014. Synthesis Report. Contribution of working groups I, II and III to the fifth assessment report of the intergovernmental panel on climate change 138. (Pachauri, R. K. and Meyer, L. A., eds). - IPCC, Geneva, Switzerland.

Jepsen, J. U. et al. 2008. Climate change and outbreaks of the geometrids Operophtera brumata and Epirrita autumnata in subarctic birch forest: evidence of a recent outbreak range expansion. - J. Anim. Ecol. 77: 257-264.

Jónsdóttir, I. S. et al. 2005. Variable sensitivity of plant communities in Iceland to experimental warming. - Global Change Biol. 11: 553-563.

Karlsson, P. S. et al. 2004. Determinants of mountain birch growth in situ: effects of temperature and herbivory. - Ecography 27: 659-667.

Kharouba, H. M. et al. 2018. Global shifts in the phenological synchrony of species interactions over recent decades. - Proc. Natl Acad. Sci. USA 115: 5211-5216.

Kingsolver, J. and Woods, H. 1998. Interactions of temperature and dietary protein concentration in growth and feeding of Manduca sexta caterpillars. - Physiol. Entomol. 23: 354-359.

Klein, D. R. et al. 2008. Climate change influences on species interrelationships and distributions in high-Arctic Greenland. - Adv. Ecol. Res. 40: 81-100.

Kramberger, B. and Klemenčič, S. 2003. Effect of harvest date on the chemical composition and nutritive value of Cerastium holosteoides. - Grass Forage Sci. 58: 12-16.

Lawton, J. 1983. Plant architecture and the diversity of phytophagous insects. - Annu. Rev. Entomol. 28: 23-39.

Leckey, E. H. et al. 2014. Oak-insect herbivore interactions along a temperature and precipitation gradient. - Acta Oecol. 61: $1-8$.

Lemoine, N. P. et al. 2013. Increased temperature alters feeding behavior of a generalist herbivore. - Oikos 122: 1669-1678.

Lemoine, N. P. et al. 2017. Responses of plant phenology, growth, defense and reproduction to interactive effects of warming and insect herbivory. - Ecology 98: 1817-1828.

Loranger, J. et al. 2013. Predicting invertebrate herbivory from plant traits: polycultures show strong nonadditive effects. Ecology 94: 1499-1509.

Memmott, J. et al. 2007. Global warming and the disruption of plant-pollinator interactions. - Ecol. Lett. 10: 710-717.

Moise, E. R. and Henry, H. A. 2010. Like moths to a street lamp: exaggerated animal densities in plot-level global change field experiments. - Oikos 119: 791-795.

O'Connor, M. I. 2009. Warming strengthens an herbivore-plant interaction. - Ecology 90: 388-398.

O'Gorman, E. J. et al. 2014. Climate change and geothermal ecosystems: natural laboratories, sentinel systems and future refugia. - Global Change Biol. 20: 3291-3299.

Parmesan, C. 2006. Ecological and evolutionary responses to recent climate change. - Annu. Rev. Ecol. Evol. Syst. 37: 637-669.

Peet, R. K. et al. 1998. A flexible, multipurpose method for recording vegetation composition and structure. - Castanea 63: 262-274.

Post, E. and Forchhammer, M. C. 2008. Climate change reduces reproductive success of an Arctic herbivore through trophic mismatch. - Phil. Trans. R. Soc. B 363: 2367-2373.

Post, E. and Pedersen, C. 2008. Opposing plant community responses to warming with and without herbivores. - Proc. Natl Acad. Sci. USA 105: 12353-12358.

Post, E. et al. 2009. Ecological dynamics across the Arctic associated with recent climate change. - Science 325: 1355-1358.

Rall, B. C. et al. 2012. Universal temperature and body-mass scaling of feeding rates. - Phil. Trans. R. Soc. B 367: 2923-2934.

Richardson, S. J. et al. 2002. How do nutrients and warming impact on plant communities and their insect herbivores? A 9-year study from a sub-Arctic heath. - J. Ecol. 90: 544-556. 
Robinson, S. I. et al. 2018. Soil temperature effects on the structure and diversity of plant and invertebrate communities in a natural warming experiment. - J. Anim. Ecol. 87: 634-646.

Roy, B. A. et al. 2004. Response of plant pathogens and herbivores to a warming experiment. - Ecology 85: 2570-2581.

Southwood, T. et al. 1986. Leaf palatability, life expectancy and herbivore damage. - Oecologia 70: 544-548.

Stein, C. et al. 2010. Impact of invertebrate herbivory in grasslands depends on plant species diversity. - Ecology 91: 1639-1650.

Turcotte, M. M. et al. 2014. Percentage leaf herbivory across vascular plant species: ecological archives E095-065. - Ecology 95: 788-788.

Tylianakis, J. M. et al. 2008. Global change and species interactions in terrestrial ecosystems. - Ecol. Lett. 11: 1351-1363.

Valdés, A. et al. 2019. A natural heating experiment: phenotypic and genotypic responses of plant phenology to geothermal soil warming. - Global Change Biol. 25: 954-962.

van Asch, M. et al. 2007. Predicting adaptation of phenology in response to climate change, an insect herbivore example. Global Change Biol. 13: 1596-1604.

Van der Putten, W. H. et al. 2010. Predicting species distribution and abundance responses to climate change: why it is essential to include biotic interactions across trophic levels. - Phil. Trans. R. Soc. B 365: 2025-2034.

Veteli, T. et al. 2002. Effects of elevated $\mathrm{CO}_{2}$ and temperature on plant growth and herbivore defensive chemistry. - Global Change Biol. 8: 1240-1252.
Visser, M. E. and Holleman, L. J. 2001. Warmer springs disrupt the synchrony of oak and winter moth phenology. - Proc. R. Soc. B 268: 289-294.

Walker, M. D. et al. 2006. Plant community responses to experimental warming across the tundra biome. - Proc. Natl Acad. Sci. USA 103: 1342-1346.

Walther, G.-R. 2010. Community and ecosystem responses to recent climate change. - Phil. Trans. R. Soc. B 365: 2019-2024.

Wardle, D. A. and Barker, G. M. 1997. Competition and herbivory in establishing grassland communities: implications for plant biomass, species diversity and soil microbial activity. - Oikos 80: 470-480.

Wardle, D. et al. 1998. Can comparative approaches based on plant ecophysiological traits predict the nature of biotic interactions and individual plant species effects in ecosystems? - J. Ecol. 86: 405-420.

Wilf, P. and Labandeira, C. C. 1999. Response of plant-insect associations to Paleocene-Eocene warming. - Science 284: 2153-2156.

Winkler, D. E. et al. 2016. Soil moisture mediates alpine life form and community productivity responses to warming. - Ecology 97: 1553-1563.

Wolf, A. et al. 2008. Impact of non-outbreak insect damage on vegetation in northern Europe will be greater than expected during a changing climate. - Clim. Change 87: 91-106.

Xiong, S. and Nilsson, C. 1999. The effects of plant litter on vegetation: a meta-analysis. - J. Ecol. 87: 984-994. 